\title{
Ecology of Insect Rearing Systems: A Mini-Review of Insect Rearing Papers from 1906-2017
}

\author{
Allen Carson Cohen \\ Insect Rearing Education \& Research Program, Department of Entomology and Plant Pathology, North Carolina State University \\ Raleigh, North Carolina, USA \\ Email: accohen@ncsu.edu
}

How to cite this paper: Cohen, A.C. (2018) Ecology of Insect Rearing Systems: A Mini-Review of Insect Rearing Papers from 1906-2017. Advances in Entomology, 6, 86-115.

https://doi.org/10.4236/ae.2018.62008

Received: December 11, 2017

Accepted: April 16, 2018

Published: April 19, 2018

Copyright $\odot 2018$ by author and Scientific Research Publishing Inc. This work is licensed under the Creative Commons Attribution International License (CC BY 4.0).

http://creativecommons.org/licenses/by/4.0/

\section{c) (i) Open Access}

\begin{abstract}
Hundreds of billions of insects are produced each year in insectaries or laboratories. These insects are reared for programs of pest control, as feed, for production of various products such as textiles and food, for research and education, among many purposes. The concept is advanced here that rearing conditions are expected to simulate the natural environments from which target insects are derived. Simply speaking, the rearing container and rearing facility are the insect's microhabitat and its overall environment. Therefore, the central premise of this paper is that rearing systems are human-made ecosystems. If our expectations are to be met, that reared insects are healthy, fit, and of high quality-simulating their wild counterparts, rearing personnel must engineer conditions that meet all the insects' needs. In this review, major advancements and progress are documented within the context of the ecology involved in artificial rearing technology. In this review, attention is paid to the food, environmental factors (temperature, humidity or water-in the case of aquatic insects-lighting, gas exchange, and soil-for soil-inhabiting insects), containment, and some special features of rearing systems that were designed to meet special needs of a target insect's biology. Because there are thousands of publications on rearing advancements, the focus is on publications that had the strongest influence on modern day insect rearing systems, as well as papers that represent historically novel rearing concepts. Where the chain of information is missing on how or from where rearing innovations were derived, papers are referenced as documentation of the various rearing system features.
\end{abstract}

\section{Keywords}

Rearing Microclimate, Feeding Systems, Containers, Genetic and Microbial Relations, Domestication 


\section{Introduction}

Vast numbers of insects are produced each year in rearing systems in support of programs worldwide. These insects are used for many purposes: sterile insect techniques, biological control, feed, medical purposes (such as wound-cleaning), commodity production (silk, honey, shellac, wax), and importantly-for research (Cohen 2015) [1]. In all these systems, the centerpiece is the insect, which is being reared under conditions that simulate nature to the extent that they provide all factors necessary for the insect to complete its life cycle in continuous generations (Figure 1). These factors include the insects themselves with all their genetic characteristics and background, appropriate food, environmental conditions, and generally a means of containment that lends itself to keeping the insects in a setting that is suitable to the insect but at the same time convenient to rearing personnel. The major purpose of this review is to explain the concept of a rearing system and how such a system must provide all the needs of the target insects that are the subjects of rearing efforts. The rearing system concept is treated as a model of processes that were developed on a per species basis for each kind of insect that is being reared successfully; and importantly, the concept is explained that the rearing system simulates-in exquisite detail-an ecosystem such as those where insects are found in nature.

\section{Search Strategy and Approach to This Review}

The information presented here is drawn from publications about various aspects of insect rearing. The papers were accessed through Web of Science, and the topics presented under subject headings of each section were derived from

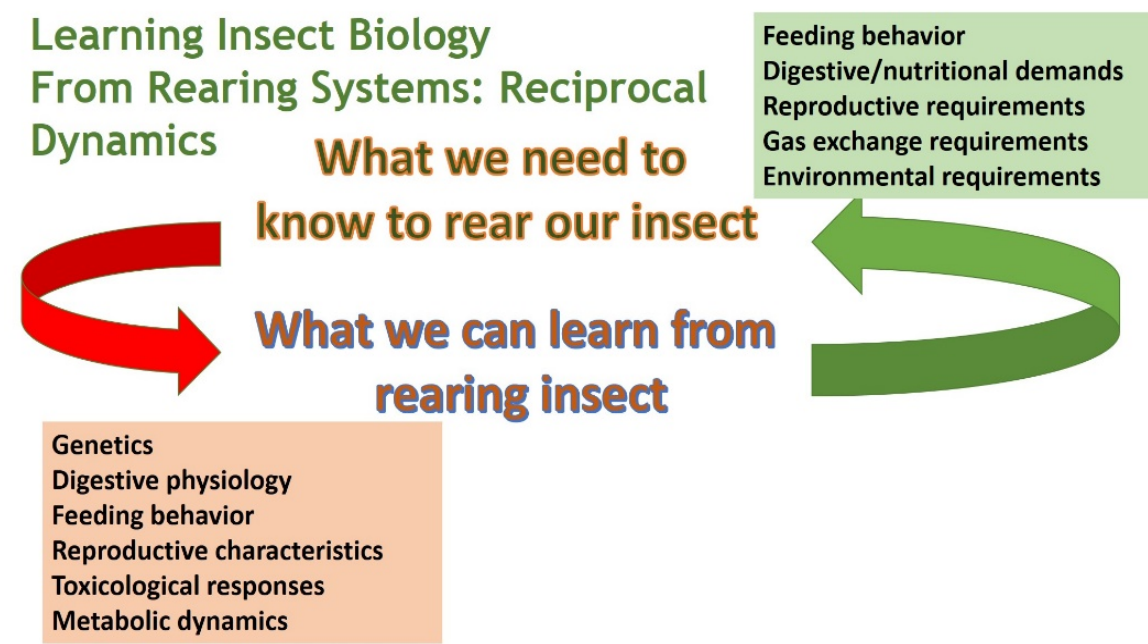

Figure 1. A model of the reciprocal nature of rearing system development in relationship with what can be learned from having a controlled process that can be applied to studies of the various factors that influence a target insect's biology. The main point of this diagram is that while a base of knowledge is needed to develop a rearing system, there is a rich array of learning outcomes that can be gained from controlled studies of insects in rearing systems. 
and explained in the publications. With the exception of some early papers written in German or French, the search was confined to papers written in English or were translated into English such as the works of Hamamura. Efforts were made to select papers based on 1) their historical (temporal) precedence, and 2) their citation record, and 3) their content in relation to other papers that were influenced. For the third factor 3), the influential papers were included in this review because of clear statements of rationale behind experimental factors. Besides information from each paper cited in this review, other details are presented, including the historical position of each topic, the number of citations for several papers, and comments about stated or presumed rationale for each rearing advancement. It is important to mention that the search of the literature does not always reveal papers on the topics expressed in the papers' titles, abstracts, or key words. As an example, I happen to have knowledge of the contributions of Dr. George D. Butler. However, in my search of "temperature" and "insect rearing" as key words, Butler's papers were not revealed by the Web of Science scope, and were brought out only after the "Butler, GD" was included in a search of "Insect Rearing" and "Temperature". Once all three of these terms were fed into the search, 34 papers by Butler on rearing and temperature were found. The only reason that this review's author could find these papers was that he knew that Butler had written several papers on the impact temperature had on rate of development. The point of this comment is that many important advances in and components of established insect rearing systems have a history that is either a) not explained in rearing literature or b) is not easily found by searches conducted through conventional search methods. In fact, it is an unfortunate fact that much of the body of practices used in insect rearing systems is a matter of an unwritten culture where practices find their way into rearing systems for given species, and tracing many of these practices remains elusive. This feature of rearing practices lends itself to the undesirable outcome that much of what is practiced in insect rearing is not vetted and not based on science or well-engineered technology.

\section{Insect Rearing Systems Defined and Characterized: Historical Perspectives and Silkworms}

The fundamental unit of insect rearing infrastructure is the insect rearing system. This all-important phrase connotes how the insect is reared: the starter population, food, containers, temperature, humidity, water system characteristics (for aquatic insects), soil conditions (for soil insects) light conditions, and all other special needs the target insect is known to have. This review does not include the incredibly complex rearing systems used in sericulture (silkworms and silk production). Sericulture was begun in China nearly 5000 years ago (Vainker 2004 [2], Barber 1992 [3], Hamamura 2001 [4] and Anonymous 2011 [5]), and apparently supersedes all other rearing systems combined in terms of the economic implications. For example, an Indian document about rearing silkworms 
(Anonymous 2011 [5]) states that sericulture employs more than 700,000 families in India alone. Besides their importance for textile industries around the world and other uses of silkworms as food and for medical applications, silkworms are also crucial components of research accomplishments. As of a Web of Science search in 2017, more than 9100 papers (more than 13,000 on "Bombyx") were published about silkworms, including a 1903 paper in the Journal of the American Medical Association about the use of silkworm gut (not silk) for sutures for kidney surgery!

In this review, the main topics of the rearing system concept will be presented, first, as general features of rearing such as containers, temperature, humidity, light, and diet and second through exploration of publications that were influential and involved in the development of several of the mass-rearing systems that underlie major programs. In this paper, rearing systems for Drosophila species, especially $D$. melanogaster will be the centerpiece of tracing the century of rearing these model organisms that have been the most thoroughly-studied and best understood metazoan.

\section{Drosophila Diet and Rearing System Development as a Historically First Modern Rearing System}

While the two oldest papers that advanced the concept of artificial diet for flesh flies were by Bogdanow 1906 [6] and 1908 [7], the first paper that lays the foundation of controlled conditions in rearing and diet presentation was the Delcourt and Guyenot 1910 [8] study that explains the importance of controlling all aspects of rearing conditions. This paper and several other pioneering diet studies by Guyenot 1913a, b, c; 1914a, b [9] [10] [11] [12] [13] made significant advances in Drosophila dietetics. For example, in Guyenot 1913a [9], the subject of the role of live microbes vs. aseptic diets was explored-a topic that had gained extensive attention in insect rearing from the earliest inquiries to the present day when insect gut microbiome evaluations abound. It is valuable to note that in the early days of diet development, the scientific community was in its "Golden Age" of microbiology and genetics, and some of the early studies on insects reflected the contemporaneous interest in the role of microbes in insect nutrition, leading to numerous studies of the essentiality of various species of microbes (e.g. Loeb 1915 [14], Loeb and Northrop 1917 [15], Michelbacher et al. 1932 [16], Baumberger and Glaser 1917 [17], Baumberger 1917a [18], b [19], 1919 [20]).

Besides the thousands of papers written about Drosophila genetics since the early $20^{\text {th }}$ Century, thousands more papers have been written about all aspects of Drosophila biology on topics ranging from ecology of these flies (Starmer and Fogelman 1986 [21] Starmer et al. 1986 [22] Anagnostou et al. 2011 [23]), and further studies on gerontology, nutrition, and countless other aspects of Drosophila biology such as feeding choice studies (Deshpande et al. 2015 [24], Ja et al. 2009 [25]. The papers by Deshpande et al. [24] and Ja et al. [25] cover the im- 
portant topics of food selection in relationship to fitness of Drosophila. The papers of Bridges and Darby 1933 [26] and Bridges 1933 [27] respectively, treat the evolution of diets for Drosophila and other aspects of rearing systems such as containers, home-made incubators, and basics of the ecology of rearing Drosophila as a laboratory organism. These papers [26] and [27] are remarkably in-depth treatments of the progress that took place in the laboratory of Thomas Hunt Morgan. The comprehensive work by Morgan et al. 1913 [28] treats the genetics discoveries with Drosophila and other species used as models of Mendelian genetics. The work done in Morgan's lab at Columbia University in the early $20^{\text {th }}$ Century shaped the field of genetics and other areas of biology, including insect rearing, to such an extent that many authors have regarded the "Fly Room" where the genetic research of Morgan's group (including, Bridges, Muller, and Sturtevant) became the subject of popular books and a movie called "The Fly Room", discussed in Anonymous 2015 [29].

\subsection{Development of Drosophila Diets and Diet-Based Rearing Systems}

Delcourt and Guyenot 1910 [8] explained that in their efforts to study the heredity of Drosophila over successive generations, a requisite for accurate determination of virtually all genetic questions was the development of controlled conditions in the rearing process. They explained that the inconsistencies of the foods used to rear the flies, where the qualities and differences in fermentation progress of raisins, bananas, and apples caused variability that was too great to allow interpretation of the genetic results that they were testing. These inconsistencies and difficulties demanded a control of the rearing system-mainly through control of diets. It was also obvious that there was a microbial involvement in Drosophila rearing as was addressed by Delcourt and Guyenot 1910 [8], Guyenot 1913a, b, and c [9], [10], and [11], and Guyenot 1914a and b [12] and [13], Baumberger 1917a and b ([18], [19], and [20]), Baumberger and Glasser 1917 [17], Loeb and Northrup 1917 [15], and by Morgan et al. 1913 [28] (as explained further by Bridges and Darby 1933 [26]). The sequence of development of artificial diets for Drosophila was: fermented fruit (generally bananas) $\rightarrow$ mashed over-ripe bananas with yeast added $\rightarrow$ banana puree extract with yeast and agar $\rightarrow$ various fruit (raisins, apples, etc.) purees with yeast and agar. Two of the major advancements that were profoundly influential to not only Drosophila rearing but to rearing countless other insect species were the addition of yeast (live or dead) and agar to provide a gelled diet.

\subsection{The Evolution of Controlled Diets for Drosophila: Microbial Relationships}

For the period of 1910 through 1933, one of the liveliest subjects of inquiry was the relationship between insects and microbes in terms of dietary issues. There was a preoccupation with establishing the role and extent of microbial involvement in the feeding biology of Drosophila and other insects, especially other 
Diptera. A major portion of this progression was explained in elegant detail by Baumberger [20] who reviewed his own and other researchers' experiments with yeasts vs. bacteria as food sources (as external or internal symbionts vs. nutrients) and live vs. heat-killed microbes. An important and illuminating part of these studies was the series of experiments that sought to tease apart the nutritional requirements that were part of the foods prior to microbial action vs. the foods post-fermentation (meant here as microbial action on media or raw materials) vs. the microbes themselves (Baumberger 1919 and Michelbacher et al. [16]). After extensive review of the literature on the roles of microbes in feeding success on natural and artificial diets, it remains difficult to conclude how much of a diet's success in meeting target insects' needs is from direct effects of microbes (changing the nutritional quality of raw materials or media components), the contribution of the original raw materials, or the nutritional value of the microbes themselves [1]. Cohen [1] concluded that these complex questions about microbe/media/microbe-media interactions must be determined on a per species basis across all insects being reared. In summation, the many diets for Drosophila that are currently being used were evolved through a series of refinements of a fruit base with yeast added along with other nutritional and functional components such as corn meal, agar, and antifungal agents. Despite considerable effort to develop completely defined (holidic) diets for Drosophila to help establish the basic nutritional requirements for this insect, and in this context, all practical diets for this insect are based on complete foods in conjunction with yeast-mainly baker's or brewer's yeast Saccharomyces cerevisiae.

\subsection{Other Aspects of Drosophila}

Rearing systems are treated in this review in separate sections on temperature and humidity, containers, and miscellaneous environmental factors (such as light, radiation, etc.). Section 5 "Environmental Factors in Rearing Systems" is a general review of rearing systems for various species, divided into the major environmental topics.

\section{Environmental Factors in Rearing Systems}

\subsection{Temperature and Humidity}

A search of "Insect rearing" and "temperature" in the Web of Science revealed 927 references. The earliest one was Smith 1931 [30], but careful scrutiny of a body of other papers where rearing conditions are treated reveal that temperature and humidity had been recognized for decades prior to the Smith [30] paper was published. For example, Bridges 1933 [27] provides an in-depth history of the treatment of temperature in the "Fly Room" at T. H. Morgan's Drosophila facilities at Columbia University had been a subject of intense effort to regulate temperature of fly rearing containers. Bridges 1933 [27] wrote:

"DURING the early work on the genetics of Drosophila melanogaster the cultures were reared on laboratory tables or on open wall shelving. This 
method gave irregular results. The cold nights of the winter season made a considerable proportion of the cultures fail to start properly, and also lengthened the generation interval."

"In 1913 I built above my laboratory table a large wooden incubator which held all my experimental cultures. This incubator was heated by carbon electric lamps placed in the lowest shelf space. The thermostat was of the 'ether-wafer' type. The expansion of the ether forced apart contacts in the heating circuit. A six inch electric fan continuously circulated air down a gap behind the shelving with return through a similar gap between the shelves and the doors."

Elsewhere in this paper and in several other places, Bridges [27] emphasized the importance of temperature regulation in rearing circumstances-that it was not only crucial for optimization and uniformity, but also to help control the very genetic factors that Drosophila researchers were trying to explore. For example, he pointed out that linkage/crossover studies are skewed by deviations in temperature. Bridges [27] wrote, "Plough's work on the effect of temperature extremes on crossing-over showed that it was necessary to maintain the temperature constant for genetic reasons as well as to improve culture conditions." Unfortunately, the recognition of the far-reaching effects of temperature and many other facets of rearing conditions is lost to the community of scholars in terms of the consequences of deviations or lack of control of rearing conditions.

A series of papers that were influential in the role of temperature in rearing systems were Smith [30], Butler [31], Stinner et al. 1974 [32], and Butler et al. 1983 [33]. These papers followed the classic line of inquiry where constant temperatures were the independent variable and the biological outcomes were observed such as rates of development, survival, and sometimes body weight or reproductive success. Visscher et al. 1979 [34] added the variable of host plant growth temperatures as well as rearing temperatures, showing that temperature, and probably other plant history factors, were influential on rearing outcomes. The more natural condition for insects under field conditions includes variable temperature, humidity, light conditions, and other parameters; however, most insect rearing has been done at a single, constant temperature. But there is a body of literature (51 references identified under the search words, "insect rearing" and "variable temperature). The earliest papers in this search were from the 1990s such as Manel and Debouzie 1997 [35] where a field-based model is reported, and more recently, Sprugeon and Brent 2016 [36] reported the value of using variable temperature. Manel and Debouzie 1997 [35] used field temperatures to model development. The use of "room temperatures" or slightly above has such extensive use that the original use of these temperatures is no longer cited. However, it remains an interesting and important fact that Bridges 1933 [27] provided a chronicle of the use of temperatures kept constant and slightly above room temperature, and he further explained the importance of the maintenance of stable, well-regulated temperatures in the synchronization of devel- 
opment and in the prevention of genetic or chromosomal alterations of the test insects.

\subsection{Light Conditions (Photoperiod, Light Intensity, Light Quality, Other Radiation)}

The term "light conditions" includes photo period, light intensity, and light quality-meaning the wavelengths provided in the rearing system [1]. Although nearly every paper that includes rearing information provides information as an incidental component in rearing conditions, only 49 papers were found with the key words, "light" and "rearing" in a Web of Science search. The range of papers under this category is broad, with papers on different qualities of light through unique papers such as the effects of light conditions on diapause in gypsy moths rearing in a spaceship [37]. The Hayes et al. 1991 paper [37] also includes other useful rearing biology information such as responses of the gypsy moth eggs and larvae to microgravity, cosmic radiation, sub-freezing temperatures and unusual vibrations (please see Figure 2). One of the most interesting results of this unusual study is that space travel conditions led to a decrease in diapause from 3 4 months to six days. In fact, the topic of diapause and the environmental factors that induce or influences it is a dominant topic in insect biology. The key words, "insect rearing" and "diapause" elicited 289 papers in Web of Science. When the term "rearing" is removed from the key words (="insect" and "diapause"), the search reveals 2075 papers. The oldest of these papers was a 1930 paper that

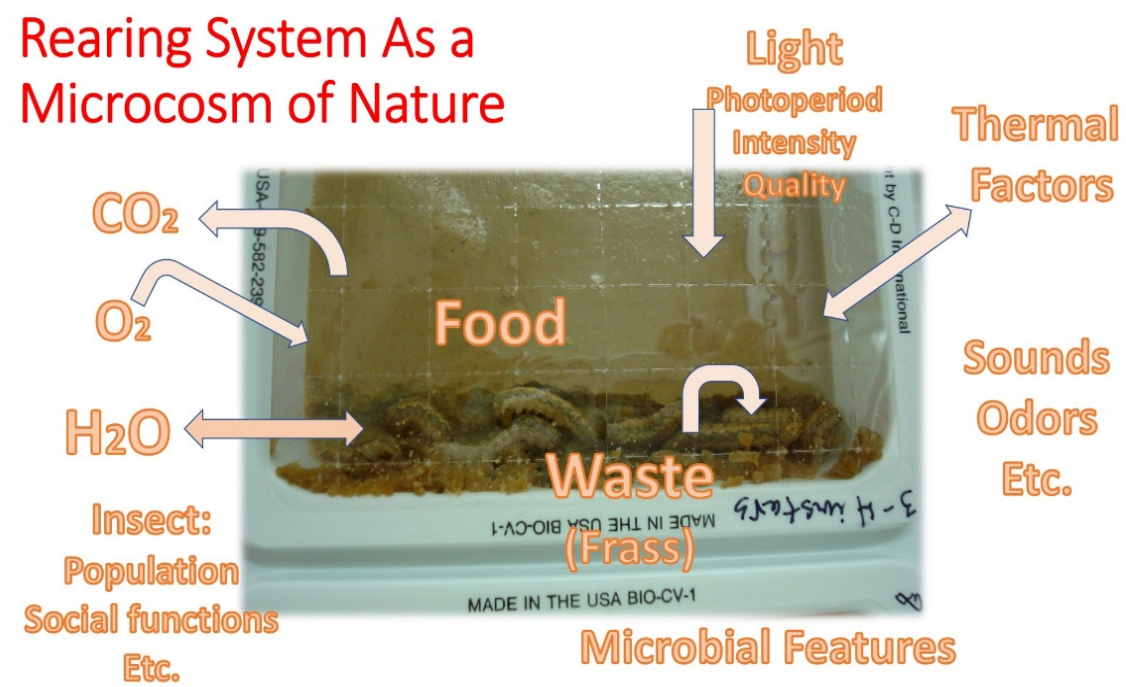

Figure 2. Diagram of the concept of the rearing system as a microcosm of nature. The insects in this photo, western bean cutworms \{Striacosta albicosta (Smith): Noctuidae: Lepidoptera\} are being reared on an artificial diet with defined environmental conditions discussed in this review. The plastic rearing container was designed to permit light, exchange of gases, and protection from stray microbes; however, the uncontrolled factors such as stray sounds or vibrations, odors, stray or unintended light, and other factors that influence the rearing process. 
describes the evolutionary background of what Roubaud [38] calls, "obligatory larval hibernation" in mosquitoes (Culex pipiens L.). The author also mentions the word "diapause" in this paper, so this topic dates back nearly 100 years. Lees [39] was a pioneer in arthropod diapause factor analysis where in 1953 he recognized the importance of light and dark phases in controlling diapause. During that same time frame, C. M. Williams discovered that the induction of diapause involved direct light stimulation to the insect brain [40], and Harris et al. [41] demonstrated that in the boll weevil, the quality of light (the narrow wavelengths) were key factors in controlling or contributing to induction of diapause. The Harris et al. group [41] also demonstrated that infrared radiation is also an important influence on diapause in boll weevils.

Interestingly, the concept of photoperiod and its influence on biological systems seems to have been developed in the early $20^{\text {th }}$ Century in relationship to plants and is first described in the literature in 1927 in the context of growth and fruitfulness of apple trees [42]. In relating photophase to insects, several papers treat various aspects of this subject including the concept of lunar phase [43], relationship between photoperiod and body size and flight capacity [44], a biochemical/nutritional basis of response to photoperiod [45], and relationship between maternal photoperiod on diapause [46] [47]. The topic of ultraviolet effects on insects has been treated in a few studies such as by McCloud and Berenbaum 1994 [48]. The importance of color and light environment as well as hatching rhythm were treated by Connor 2006 [49], Collins et al. 2008 [50], and Tao et al. 2017 [51], respectively. Light intensity has been recognized as a key factor in many aspects of insect biology [52], and this recognition took place in the earliest studies of rearing Drosophila [27]. Several laboratories use continuous light, rather than light/dark photoperiods [53] [54] [55]. However, too often rearing facilities use light conditions that are based on conditions that have not been properly documented or vetted on the basis of their target insect's biology. When rearing personnel are trying to develop a rearing system for an insect that is new to them, they simply depend upon conditions that were successful in other laboratories-often this information is passed on by word of mouth [1].

\subsection{Gas Exchange, Metabolism, and Energetics}

While the literature on gas exchange, metabolic dynamics, and energetics is vast, few papers deal directly with these parameters in rearing systems. Reverting to the axiom that the rearing system is our domesticated insects' ecosystem, we are reminded that all the insects' needs must be met, including gas exchange and their related aspects: metabolism and energetics. This means that for terrestrial insects, the containers must meet the $\mathrm{O}_{2}$ and $\mathrm{CO}_{2}$ requirements while diets and insects are protected from desiccation due to excessive water loss. This also includes the cases where insects tunnel into diets or are otherwise positioned where insufficient oxygen supplies render the target insects into anoxic states or where excessive carbon dioxide prevents normal metabolic functions, including 
$\mathrm{pH}$ regulation of internal fluids. The intimate relationship between nutrient utilization and gas exchange also underlies the rearing system, leading to a relationship between respiratory quotient $(\mathrm{RQ})$ and the insect's nutritional profile. In this context, it is important to recognize that the nutrient profiles of artificial diets can affect the insects' oxygen requirements, where the insects' inherent nature as a "lipid specialist" vs. a "carbohydrate specialist" can drive the insect to increase its oxygen demand, if there is excessive and unavoidable lipid (especially fats) in the diet [55] and [56]. It is also crucial to recognize that other factors in the rearing environment such as temperature have profound influence on oxygen demands and carbon dioxide dynamics [55] and [56]. An excellent explanation of the relationships between metabolic rate variation in tsetse flies is found in Klok et al. [57], Terblanche and Klok 2004 [58], and Harak et al. 1998 [59] provide a compelling overview of stress in mealworms and the resulting changes in caloric differences in stress vs. non-stress conditions. It is worth noting that a series of interesting papers has been produced by the Terblanche group over the past two decades, and many of these papers on thermal tolerance, metabolic rates, and related topics are of interest to researchers in the rearing community in the context of food utilization, stress, and evolutionary perspectives of metabolic responses to rearing/environmental conditions. Schilman et al. 2011 [60] and Frazier et al. 2001 [61] treat the important relationship between temperature and oxygen demands and anoxia as related to temperature.

\subsection{Water (Humidity and Aqueous Conditions)}

\subsubsection{Atmospheric Humidity (Terrestrial Conditions)}

Often, rearing papers include information about humidity along with the temperature conditions (Smith 1931 [30]). However, several papers include studies of specific effects of various humidity conditions (for example Subramanyam and Hagstrum 1991 [62] and Cothran and Gyrisco 1966 [63]). It can be summarized that, in general, reports of humidity are nearly as numerous as description of temperatures in rearing publications.

\subsubsection{Aquatic Insects and Larvae of Mosquitoes}

The literature on rearing aquatic insects is too expansive to be covered comprehensively here. In fact, the key words of "mosquito" and "rearing" produced 1099 references in the Web of Science search, dating from Phillips and Swingle 1940 [64] through hundreds of papers in the past few years, alone. The topics in these papers include diets for aquatic insects, and they also contain extensive information on food regimens (Inoda et al. 2009) [65] special containers for water-dwelling species, including papers on simulating moving water (lotic) systems (Keiper and Foote 1996) [66]. Comprehensive reviews of mosquito rearing such as Williams and Williams 2017 [67] and Benedict et al. 2009 [68] are useful for summarizing the most widely-used systems of containers, water-handling, and other special features of aquatic systems such as filtering, $\mathrm{pH}$ management, lighting, and waste removal. Also, the text book on aquatic insects edited by 
Merritt, Cummins, and Berg 2008 [69] is an excellent compendium on all the special requirements of aquatic insects from various habitats.

\subsection{Containers}

Using the key words, "Insect Rearing" and "containers": 76 papers were found. What may seemingly be a minor part of insect rearing systems-containersmust be recognized as one of the most consequential parts of the rearing system/ecology concept. A good container must serve the target insect's needs, including thermal features, humidity accommodation, gas exchange, being hospitable to developmental and reproductive needs, and any other microhabitat factors inherent in the insect's biology. The container must also serve the needs of the rearing personnel, including availability of the containers at a reasonable cost, storage accommodation, ease in access to the insects, and cleaning requirements. The comments of one of the earliest papers on rearing (Burgess 1908 [70]) these comments were made:

One of the serious problems which it was necessary to solve in order to successfully rear the parasitic and predaceous insects which were being shipped from Europe to prey on the gypsy and brown-tail moths was to secure apparatus by means of which these insects, as well as their hosts, could be successfully reared in large numbers. All of the old style equipment in general use by entomologists for rearing work was tested, but in many cases it was found that radical improvements were necessary in order to accomplish the results desired. It was of primary importance to place the insects under as nearly as possible natural conditions and at the same time to keep them in confinement where they could be studied and observed and not allowed to escape from captivity.

In the last paragraph of the paper, Burgess [70] elegantly stated the concept that the rearing conditions must simulate nature-but with conditions that meet the convenience of the investigator (or the rearing system personnel):

It is perfectly true that breeding devices must be used which are especially adapted to the habits and character of the insects to be studied, and it may be desirable to modify these cages in such a way as to suit the special needs of the investigator.

From these earliest treatments of containers (or rearing devices) throughout the history of insect rearing, a variety of container-types is remarkable. As is the case for many rearing innovations, the rearing system for Drosophila spp. was often the earliest model. For example Bridges (1933) [27] wrote about the early rearing system in the laboratory of T. H. Morgan (a famous facility that came to be known as "The Fly Room.")

In the early work on the heredity of Drosophila the cultures were raised in quart fruit jars, in quart milk bottles, and in a very miscellaneous collection of museum jars and other laboratory glassware. The great difficulty was in 
getting the flies out of these cultures for etherization and examination. By 1913 pint and half-pint milk bottles had become standard, largely on account of their uniformity of mouths, their heavy, strong glass and the ease with which they could be procured.

Bridges [27] went on to explain in elaborate detail the other advantages of half pint milk bottles and the rationale behind the refinements, including the importance of being able to clean and even sterilize the milk bottles to prevent carryover of insects from a previous generation as well as for sanitation. For example, he describes the modification of the standard round milk bottle to a more convenient and efficient square shape:

In 1916 I made experiments to determine the optimum area of culture surface, and concluded that the pint milk bottle was best for the flies, but the half-pint, which was not far inferior in that respect, was greatly superior in ease of handling, etc. Accordingly in 1917 I drew designs and made a wooden model of a special bottle, having the floor area of the pint bottle and the height $(135 \mathrm{~mm})$ and other good features of the half-pint bottle.

Bridges (1933) [27] went into further detail about the optimization of container design, including his developing an agreement with a bottle manufacturing company to produce a special, custom-made square version of the half-pint bottle. Many laboratories continued to use the glass milk bottles until the later $20^{\text {th }}$ Century when the convenience and low expense of plastic containers overtook glass bottles in popularity.

After Bridges' (1933) [27] paper, there are very few papers that treat containers as a specific, central topic. However, as is the case with many aspects of rearing systems publications, there is a wealth of information about rearing containers that can be found in publications if they are scrutinized. Several papers that treated container specifications and that were influential or that presented novel containment systems among the larger body of rearing papers are Shorey 1963 [71], Shorey and Hale (1965) [72], Tillman et al. 1997 [73], Ignoffo and Boening 1970 [74], Cothran and Gyrisco 1966 [63], and Singh and Surrey 1980 [75]. The Ignoffo and Boening 1970 [74] paper introduced the multiple cell rearing tray which became a tremendous improvement in mass-rearing containment systems, including the innovation of using the food industry's form-fill-seal technology to make various plastic trays such as the 32-cell tray and the 8-cell tray, which greatly reduce handling of individual cups. Several laboratories invested in the purchase of tray-making form-fill apparatus to ultimately reduce costs of tray purchases (Tillman et al. 1997 [73], Cohen and Staten 1996) [76]. As Tillman et al. (1997) [73] describe, the multiple-cell trays [73] required specially-adapted lidding materials that consisted of a plastic material with a glue adhesive that was either a self-sticking glue or a heat-activated glue. Such lidding was designed to include pre-perforated zones fitted to each rearing unit, allowing adequate gas exchange while reducing the loss of water from the diet and insects. 
Of course, these gas exchange demands must be met and balanced with protection from excessive water loss through evaporation from the diets and the insects, and for this appropriate containers must be designed such as those described by Tillman et al. [73].

\subsection{Reproductive Needs in Rearing Systems}

It is clearly a crucial responsibility of rearing system personnel to provide suitable conditions to allow their target insects to perform the reproductive functions that allow them to sustain continuous generations of offspring. These conditions include mating accommodations, suitable oviposition circumstances, and appropriate hatching and developmental requirements. A search of the key words, "insect rearing" and "reproduction" yielded 539 publications (from 1979-2017) with a large range of topics, many including diet quality/nutritional relationships, microbial interactions, or environmental conditions such as lighting and temperature. However, the focus of this topic in the current review is more confined to conditions that affect mating success and oviposition factors. So, for example, the adult cage configuration that was conducive to mating and supply of liquid diet (sugar or honey solution) was presented by Yamamoto 1969 [77] and by Bell and Joachim 1976 [78] for rearing two lepidopteran species (Manduca sexta Sphingidae: Lepidoptera and Pectinophora gossypiella Gelechiidae: Lepidoptera). These papers ([77] and [78]) as well as Patana 1977 [79] also provide suggestions for oviposition substrates such as waxed paper or paper toweling that lend themselves to convenient substrates for collecting and processing the eggs laid by the various moth species. Similar requirements are met by use of ice-cream cartons with organdy lidding material for lacewing rearing as described by a number of authors, starting with Ridgway et al. 1970 [80]. A unique and highly efficient ovipositional accommodation was designed by Patana (1982) [81] who reported using packets made from Parafilm ${ }^{\mathrm{Tw}}$ covering filled with a carrageenan gel. The packets were laid on top of wire or organdy mesh cage tops, allowing the plant bugs (Lygus hesperus Knight, Miridae: Hemiptera) to oviposit into the packets where the eggs could absorb moisture as they would under conditions where the insects ordinarily would oviposit into plant tissues. This system allows the insect rearing staff to harvest packets without opening the cages or otherwise disturbing the insects, and the packets were reported to contain more than a thousand eggs per $100 \mathrm{~cm}^{2}$ surface area. The insect rearing literature contains hundreds of specialized reproduction/oviposition accommodations, too numerous to describe here but all clearly part of the need to meet on a per case basis various insects' needs.

\section{Microbial Aspects of Rearing Systems (Pathogens, Symbionts, Contaminants)}

The topic of microbial aspects of rearing systems involves well over a thousand papers on pathogens, symbionts, and contaminants. The study of microbial rela- 
tionships in insects in rearing systems has been a topic of research focus since the earliest papers by Bogdanow $(1906,1908)$ [6] and [7]. The scope of papers written about "insects" and "microbes" exceeds 1000, with many more papers written about the overlap of these areas but not located by a search of these key words. More recent attention, starting with a review of insect gut bacteria not of pathogen status, was written by Dillon and Dillon 2004 [82]. Since that review, 13 years ago there were 188 papers located with the keywords "insects" and "microbiome". Clearly, the topic of microbial aspects involved in rearing systems is too large for the present paper, but it is intended here that the cursory review of microbial involvement in microbial aspects of rearing systems will provide a start for investigators to probe this very rich field in more detail. The topic of microbial aspects of insect rearing had been treated extensively by the late Peter Sikorowski, and two of the most comprehensive, practical, and in-depth reviews are to be found in the two chapters by Inglis and Sikorowski 2009 [83] [84].

\subsection{Pathogens in Rearing Systems}

As in nature, pathogens can have a huge influence on insect populations in rearing systems, and the close proximity of insects in captivity and conditions dislocated from natural epidemic control renders rearing systems into a status of ripe target of obligate and facultative pathogens (Inglis and Sikorowski 2009) [83]. Inglis and Sikorowski [84] explain several mechanisms of pathogen transfer in rearing system, with examples from viral, bacterial, protozoan, and fungal microbes. The Web of Science search of "rearing" and "pathogens" revealed 1403 papers over the past 60 years. A search of "insect" and "pathogens" revealed more than 8000 papers, many of which included insects held in rearing conditions.

\subsection{Symbionts in Rearing Systems}

The importance of symbionts in successful rearing programs cannot be overemphasized in terms of fitness or even the survival of colonized insects (Cohen 2015) [1]. Depending on the taxa of the target insect species, symbionts may be internal or external. Internal symbionts may be part of the insect's gut microbiome (Dillon and Dillon) [82], or they may be held by specialized structures in the insect's hemocoel in mycetocytes or mycetomes (Douglas 1998, [85]) Douglas and Prosser 1992 [86], Sandstrom et al. 2001 [87]; Nishide et al. 2017 [88], for a more recent review of this topic. External symbionts are found in wood-consuming beetles such as ambrosia beetles (discussed by Klepzig and Six 2004, [89], Six 2012 [90], Biedermann, and Rohlfs, 2017 [91]) where fungus-bearing external structures known as mycangia are adapted to inoculation of fungi into wood galleries.

\subsection{Microbial Contaminants in Rearing Systems}

Because of the essential nature of rearing systems where highly nutritional diets 
are kept for extended periods under environmental conditions that are optimal for microbial growth, contamination becomes one of the most prominent challenges to rearing personnel. These conditions are further made problematic by the density of insects in most rearing systems and the proximity of fecal materials (frass) to the insects. The issue of contamination, therefore, has received attention since the earliest years of rearing efforts. For example, Bridges and Darby 1933 [26] discussed the extensive efforts to manage mold in diets used for Drosophila rearing in the Fly Lab of T. H. Morgan, dating back to 1913. The control of contamination has included modification of the media (diets) to make them less susceptible to microbial contaminants by using sanitation (Sikorowski and Lawrence 1994 [92], Inglis and Sikorowski 2009a [83] and 2009b [84], Sikorowski and Lawrence [92], Inglis and Cohen 2004 [93]), pH (Funke 1983 [94], Cohen 2015 [1]), water activity or use of humectants (Ludemann et al. 1979 [95], Cohen 2015 [1]), or antimicrobial chemicals (Singh and House 1970 [96], Zha and Cohen 2014 [97] Funke 1983 [94], Vail et al. 1968 [98], Ludemann et al. 1979 [95], Alverson and Cohen 2002 [99], Inglis and Cohen 2004 [94], Zha and Cohen 2014 [97], and Cohen 2015 [1]).

\subsection{The Special Case of Wolbachia}

A special case of microbial influences on insects in rearing systems is the complex interactions of the bacterium Wolbachia spp. with their insect hosts. The search of key words, "Wolbachia" and "insect rearing" revealed 151 papers, the earliest ones dating back to the mid-1990s (Sinkins et al. 1995) [100]. The comprehensive review by Werren 1996 [101] still serves as an excellent base of information about the various biological effects of Wolbachia such as cytoplasmic incompatibility, influences on sex ratios, feminization of males, induction of parthenogenesis, and various other fitness parameters related to both field and laboratory interactions. The scope of Wolbachia as a "manipulator of invertebrate biology" is further explained by Werren et al. 2008 [102]. The older review by Werren (1996) [101] is updated by Rani et al. 2009 [103], Goettel and Inglis 2006 [104], and most recently by Lindsey and Stouthamer 2017 [105]. Also, because Wolbachia presents such a mixed case of a beneficial effects vs. potential harmful effects of Wolbachia, it is valuable to have information about possible management strategies for this bacterium such as the study by Kyei-Poku et al. 2003 [106] dealing with heat treatment or antibiotic therapy to eliminate Wolbachia.

\section{Genetics}

First, it should be explained that although genetics is not a component of the ecology of reared insects per se, it must be considered in the context of domestication and selection (deliberate or inadvertent) for traits that relate to ecological parameters such as responses to temperature, light conditions, or nutrients. A search of "insect rearing" and "genetics" revealed 119 results dating from 1976 to 2017. Clearly there are thousands more papers on genetics of reared insects dat- 
ing back to the late $19^{\text {th }}$ or early $20^{\text {th }}$ Centuries, especially if Drosophila genetics are considered in relationship to various rearing conditions such as temperature effects, diet, or countless other parameters. For example the basic studies of Morgan et al. 1913 [28] put the foundation of Drosophila genetics in the context of controlled rearing conditions into a systematic framework as do countless papers on genetics of colonized insects. This raises an important point emphasized throughout the writing of the late Dr. A. C. Bartlett who was a leading researcher and scholar on the topic of insect domestication and its results (Bartlett 1984 [107] and 1994 [108]). Some more recent papers such as Thomas (1993) [109] treat the specific interactions between controlled rearing conditions and biological or fitness outcomes in rearing systems for screwworms, and the studies of Bush and Neck (1976) [110] give valuable perspectives of the ecological aspects of genetics in mass-rearing settings. Studies of these kinds of interactions are powerful reminders of the importance of seemingly minor differences in rearing conditions in the biological fitness outcomes and realization of genetic potential of reared insects. Benedict et al. [68] cover this topic in a systematic review of rearing conditions and mosquito production and quality. The topic of genetics in rearing systems and the interplay genetic and domestication factors is too large to be properly treated in a general review such as the current paper.

\section{Case Study 1: Rearing Systems for Screwworms}

While Drosophila rearing systems are dominant influences on the development of insect rearing for research purposes, screwworm rearing systems are basic to the most comprehensive success in practical insect control otherwise known as applied pest management, an important part of integrated pest management (IPM) programs (Babilonia and Maki 2017 [111], Brown 1984 [112], Chaudhury and Alvarez 1999 [113], Chaudhury et al. 2009 [114], Hendrichs and Robinson, 2009 [115], and Parker 2005 [116]). The sterile insect technique (SIT) was originally conceived by Knipling 1955 [117] and was made possible by the development of economically feasible artificial diet and the diet-based mass-rearing system originated by Melvin and Bushland 1936 [118] and 1940 [119]. The screwworm SIT program has been one of the most successful insect control systems in human history, where complete eradication has been accomplished throughout most of North America (Babilonia and Maki [111], Parker [116]), and the success and processes of this program have been instrumental as influences in control of other damaging insects such as various tephritid fruit flies, pink bollworms, and mosquitoes (Parker [116]).

\subsection{Evolution of Screwworm Rearing Systems}

The most celebrated and oldest system of sterile insect technique (SIT) is the one associated with the mass production of sterile screwworm flies, Cochliomyia hominivorax (Coquerel) (Brown 1984 [112]; Babilonia and Maki Website [111]; Parker 2005 [116]). In fact, the demonstration that SIT is feasible is unquestionably thanks to the various successes of the screwworm program. This success 
starts with the concepts advanced by E. F. Knipling (1955) [117] and became one of the most successful and well-recognized insect control strategies, largely due to the remarkable success in mass-rearing technology developed between 1936 and the 1960s. Babilonia and Maki [111] discuss the eradication of this pest in the US, Mexico, and now throughout most of Central America, and these authors also describe the responses of the screwworm program to outbreaks of this pest in Africa. Parker's chapter [116] on the development of screwworm rearing updates many of the changes adopted in screwworm rearing programs, including the treatment of the evolution of the mass-rearing system described by Brown 1984 [112]. The Parker chapter, along with the other contents of the Dyck et al. 2005 book, offers a most valuable resource in summarizing the dynamics of changes in the mass-rearing techniques, including the process control and quality control applications to the highly successful mass-rearing systems for screwworms, and other insect species that are produced for SIT programs. The Parker chapter presents valuable economic data in the context of total program effectiveness and in terms of the great leverage of seemingly incremental changes in rearing procedures that effect significant cost savings that help make the SIT programs financially feasible.

Parker [116] includes wide-ranging information as well as granular details in matters of insectary design, management of genetic diversity, process- and quality control, as well as details of automation of sexing, diet-production (including diet development issues), insectary environmental issues, treatment of risks of escape of fertile individuals, and well-being of personnel who spend nearly a third of their working lives in the mass-rearing facility.

\subsection{Evolution of Screwworm Diets and Diet Presentation}

The earliest diets for screwworms, as described by Melvin and Bushland [118] [119], consisted of water, ground beef, citrated beef blood, and formalin which supported 88 consecutive generations over four years with a yield of about 4,000 pupae per week. Melvin and Bushland 1940 [119] also reported smaller scale rearing of screwworms with a sterile diet of egg yolk and whole milk in a soft agar kept sterile with formalin. The early diet's yield of 4,000 individuals per week was amplified to more than a half billion per week, thanks to the many improvements in diet, automation, and other features of rearing advancements (Brown 1984 [112]). Although the modifications in diet and the evolutionary progress, which was often seemingly incremental, are too many to cover adequately here, many of the changes in rearing media include substitution of other ingredients for the meat, changes in the semi-solid diet to a liquid form, using whole egg and calf milk supplements, and media for stabilizing the liquid diet, such as cellulose, cellulose acetate, shredded paper, cotton, bagasse, corn cob grits, or other locally available materials. Gingrich [120] presents a useful comprehensive review of earlier diet improvements. Several improvements in the liquid-stabilizing domain of diet components were discussed by Chaudhury and Alvarez 1999 [113] and Chaudhury et al. 2011 [114]. These works document the 
importance of texture and physical matching of the insects' feeding requirements, beyond simply meeting nutritional needs. Besides the mass-rearing science and technology in the screwworm SIT system, scores of research studies on the physiology and genetics of mass-reared insects have been stimulated by the impetus of the huge, economically-important rearing programs. There are reciprocal benefits of such studies as Bush et al. 1976 [121] and the technological advancements of the large-scale systems where insects have become highly, though inadvertently, domesticated.

It should be noted that the screwworm mass-rearing system faced many problems that needed to be addressed as the scope, economic and biological feasibility of the program could be satisfied. Some of these improvements or breakthroughs were described in seemingly incremental reports in the peer-reviewed literature (most often in the Journal of Economic Entomology).

\section{Case Study 2: Rearing Systems for Pink Bollworms}

Currently, the largest program in rearing pink bollworms (Pectinophora gossypiella Gelechiidae: Lepidoptera) is the USDA, APHIS facility in Phoenix, AZ (USA). The Pink Bollworm Facility has been in operation since the early 1960s dedicated to production of pink bollworms for several research projects and largely for programs dedicated to the management of these serious pests. As well as being a model for innovation and progress in insect rearing systems, the Phoenix facility has been a model of coordinated support from the private sector, several state governments, and national governments in the US and Mexico. The management programs include very successful eradication efforts in Arizona, California, New Mexico, Texas, and several states in Mexico. The management strategies include sterile insect techniques, pheromones, cultural practices, biological control, genetic selection/transgenic technology, and small volume applications of pesticides in an overall program of integrated pest management (IPM). Tens of millions of dollars per year have been dedicated to the pink bollworm program, and hundreds of workers at all levels from entry level personnel to senior leadership positions. A recent article in Western Farm Press (http://www.westernfarmpress.com/cotton/pink-bollworm-eradication-cotton-2 017) explains the history of pink bollworm management and ultimately eradication in the southwestern cotton belt. From my perspective as a student of insect rearing history, the single most indispensable feature of this program's success is the mass-rearing system for pink bollworms. The characterization of the evolution of this rearing system is a prime example of the issues that need to be understood.

\section{Evolution of Pink Bollworm Diets as Centerpieces of Rearing Systems}

During the 1950s, several papers were published on the basics of pink bollworm diets and rearing, starting with a nutrition study by Beckman et al. 1953 [122]. Erma Vanderzant was a major contributor to nutritional research on cotton boll 
weevils and pink bollworms much of her attention was dedicated to development of our understanding of the basic nutrition of these insects, with a stated goal of applying nutrition to practical mass-rearing systems (Vanderzant 1957 [123] and 1958 [124], Vanderzant and Reiser 1956a [125] and 1956b [126], Vanderzant et al. 1957 [127] and 1959 [128]). One of the most successful advancements in insect rearing, the introduction of wheat germ to pink bollworm diets, is a product of the Vanderzant-led research efforts. It is an important fact that the introduction of wheat germ to insects diets was in a paper on boll weevil diets (Vanderzant et al. 1959 [128]), though in this report it the wheat germ did not lead to the remarkable success that it did in the debut of this material in the pink bollworm diet (Adkisson et al. 1960b [129]). In fact, the only positive effect in the boll weevil diet report was that wheat germ had unexpectedly stimulated oviposition, which previously could only be induced with extracts from cotton bolls. Though the rationale for using wheat germ in the boll weevil diet and the pink bollworm diet was not stated by Vanderzant et al. 1959 [128] nor by Adkisson et al. 1960b [129], the thinking that led the Adkisson team (which included Erma Vanderzant) to use wheat germ in the pink bollworm diet turned out to be in retrospect revolutionary in terms of the hundreds of species reared on diets based on wheat germ and the billions (possibly trillions) of insects whose production is successful thanks to this single component. It is of further interest that wheat germ later turned out to be a key component in boll weevil diets, once these wheat germ diets were supplemented with cholesterol (Vanderzant 1967 [130]).

Other important steps in the evolution of pink bollworm rearing include the addition of soy flour to the diet as mentioned by Stewart (1984 [131]) and the adoption of several anti-microbial agents (Ouye 1962 [132]; Stewart et al. 1976 [133]). Tracing the origins of soy components now used in pink bollworm diet presents a complex forensic story. Stewart 1984 [131] did not discuss the reasons or sources that influenced adding soy flour to the diet he described as stemming from Ouye 1962 [132] (a wheat germ diet based on Adkisson et al 1960a [134]). Stewart 1984 [131] cites Shaver and Raulston 1971 [135], so it seems that the later paper influenced that adoption of soy flour into the pink bollworm diet, making production of the insects more economical and reliable than if the diet was limited to casein as a protein source. Soy flour is a major component of the current pink bollworm diet as it is an important part of dozens of other insect diets. The nutritional and functional basis of soy flour is discussed thoroughly by Cohen 2015 [1]; but suffice it to say that it is an exceptionally nutritious material, which supplies all the amino acids, many vitamins, minerals, and offers textural features such as fiber and feeding stimulants. It is evident that use of soy components in insect diets began in Japan in efforts to develop artificial diets for silkworms (Bombyx mori) as described by Hamamura 2001 [4] (a translation of a book on silkworm diets written in the 1970s) and Ito and Horie 1962 [136]. Redfern 1963 [137] reported using soy protein isolate in a diet for red leaf roller, and the first report of soy flour in what I am calling Western literature was by 
Shaver and Raulston 1971 [135], who reported excellent success in using soy flour (raw, toasted, and soy meal) to replace dairy casein. In several reports from the Japanese literature or from Japanese research groups, a material called soy casein was used as a protein source for silkworm diets. These comments raise a point that has become apparent to me that there is a wealth of information on excellent insect diet and nutrition science that resides in Japanese, Chinese, Indian, and possibly other Asian literature but remains unavailable to those of us who have not accessed this body of information. The fortunate experience that I had in getting access to the Hamamura translation (2001) of a remarkable book on Silkworm Rearing on Artificial Diet [4] is a testimony to the point about the gap in rearing literature that fails to include the accomplishments and excellent science in Asian literature and culture on insect rearing.

The diet for pink bollworms was initially produced in $\mathrm{kg}$ or sub-kg quantities, then progressed to 50-100 kg batches made in steam kettles (Stewart 1984) [133]. The development of rearing technology in the early stages (1960s) is reviewed by Martin 1966 [138]. Between the 1970s and the mid-1990s, the production of pink bollworms was limited to about a million adult insects per day, largely due to scope of diet production. The transition to diet production through adoption of the twin screw extruder derived from the human food industry allow production of diet adequate to support 25,000,000 pink bollworms per day (Edwards et al. 1996 [139]. However without the automation (e.g. Miller et al. 1996 [140] and Richmond and Martin 1966 [141]). The pink bollworm rearing system includes scores of innovations such as automated egg surface sterilization, scale collection systems that protect workers and insects from the hazards and pathogens in scales, Honeycomb (=Hexcel, Stamford, CT 06901) for pupation sites and pupal collection, form-fill seal machine-produced containers for larvae, refrigerated adult collection sites, disposal of tons of scales per year, oviposition technology using sterile paper toweling fitted to vacuum-connected adult mating and oviposition containers, and many other features [131]. Stewart 1984 [131] summarized the progress towards automation for a period from 1970 to 1979 when production went from about 0.5 million per day to about 1.5 million per day. But when the extruder technology was adopted (Edwards et al. 1996 [139]) production was able to leap to 10 to 20 times the number for 1979 .

\section{Conclusions}

An important point made by Cohen [1] about rearing systems, is that there is a reciprocal relationship between what we need to know to develop a rearing system and what we can learn about our insects once we have an operating rearing system (Figure 2). This point emphasizes the concept of control as a fundamental need in developing a successful rearing system and the fact that controls in experiments with target insects can yield a level of understanding that could not be developed for insects in the field.

In a collection of essays on the topic of relationships between ecology and evolution, Hutchinson 1965 [142] explains and richly illustrates how environ- 
mental forces interplay with and shape genetic and ultimately evolutionary outcomes in nature. We can adapt Hutchison's terms to state that rearing systems can be regarded as the "ecological theater" as a shaping force for the insects that we rear for various purposes. The rearing specialist who fails to consider the nature and power of the shaping forces in the rearing constraints that we place on our insect subjects is apt to lose control over the products of the rearing system. In setting up an insect rearing system, entomologists select a highly limited population - a subsample of a much larger population (Mackauer 1972 [143] and Bartlett 1984 and 1994 [108] [109]), violating a major premise of the Hardy-Weinberg Equilibrium Principle, and we subject the insects to intense (though often unrecognized) selection pressures. The selection parameters and profiles were reviewed in this paper where temperature, humidity, container configuration, light intensity, diets, and countless other factors were imposed upon the insects that are being produced. There is often, in rearing systems, no attention to densities of insects and how density-dependent pressures may affect the outcome of our rearing efforts. It was the intention of this paper to provide a sample of the complex ecological conditions that are present in rearing systems, and it is hoped that this albeit cursory summary of the various conditions will enhance the realization of rearing specialists and the community they serve that the insect-products of rearing systems have been subjected to stresses and selective pressures that may lead to deviation from the expected outcomes.

\section{References}

[1] Cohen, A.C. (2015) Insect Diets: Science and Technology. 2nd Edition, CRC Press. Boca Raton, FL. https://doi.org/10.1201/b18562

[2] Vainker, S. (2004) Chinese Silk: A Cultural History. Rutgers University Press, New Brunswick, New Jersey, 20.

[3] Barber, E.J.W. (1992) Prehistoric Textiles: The Development of Cloth in the Neolithic and Bronze Ages with Special Reference to the Aegean. Princeton University Press, Princeton, 31.

[4] Hamamura, Y. (2001) Silkworm Rearing on Artificial Diet. Science Publishers, Enfield, New Hampshire. (Translated from Japanese)

[5] Anonymous (2011) History of Sericulture. Government of Andhra Pradesh (India), Department of Sericulture. http://www.yourarticlelibrary.com/zoology/sericulture-in-india-history-types-of-sil ks-and-life-history-with-diagrams/23826

[6] Bogdanow, E.A. (1906) About the Breeding of Larvae in Usual Flesh Flies (Calliphora vomitoria) in Sterilized Nutrients. Archives of the European Journal of Physiology, 113, 97-105. https://doi.org/10.1007/BF01677331

[7] Bogdanow, E.A. (1908) About the Dependence of the Growth of Larvae of Bacteria and Enzymes and about Variability and Inheritance in the Flesh Flies. Archives of Anatomy and Physiology. Abstract, Supplement, 1908, 173-200.

[8] Delcourt, A. and Guyenot, E. (1910) The Possibility of Studying Certain Diptera in a Defined Environment. Comptes rendus hebdomadaires des séances de l'Académie des sciences (0001-4036), 151, 255-257. 
[9] Guyenot, E. (1913a) A Biological Study of a Drosophila ampelophila Low Fly I-The Possibility of an Aseptic Life for an Individual and the Line. Comptes rendus des séances de la Société de biologie et de ses filiales (0037-9026), 74, 97-99.

[10] Guyenot, E. (1913b) Biological Study in a Fly, Drosophila ampeltophila Low II-The Role of Yeast in Food. Comptes Rendus des Seances de la Societe de Biologie et de Ses Filiales, 74, 178-180.

[11] Guyenot, E. (1913c) Biological Studies on a Fly, Drosophila ampelophila Low V-Nutrition of Adults and Fertility. Comptes rendus des séances de la Société de biologie et de ses filiales (0037-9026), 74, 332-334.

[12] Guyenot, E. (1914a) Biological Studies on a Fly Drosophila ampelophila Low. Need to Create a Definite Feeding Environment. Comptes rendus des séances de la Société de biologie et de ses filiales (0037-9026), 76, 483-485.

[13] Guyenot, E. (1914b) Primary Trials of Determination of an Artificial Nutritive Environment for the Raising of a Fly, Drosophila ampelophila Low. Comptes rendus des séances de la Société de biologie et de ses filiales (0037-9026), 76, 548-550.

[14] Loeb, J. (1915) The Simplest Constituents Required for Growth and the Completion of the Life Cycle in an Insect (Drosophila). Science, 41, 169-170.

https://doi.org/10.1126/science.41.1048.169

[15] Loeb, J. and Northrop, J.H. (1917) On the Influence of Food and Temperature on the Duration of Life. Journal of Biological Chemistry, 32, 103-121.

[16] Michelbacher, A.E., Hoskins, W.M. and Herms, W.B. (1932) The Nutrition of Flesh Fly Larvae, Lucilia sericata (Meig.). Journal of Experimental Zoology, 64, 109-131. https://doi.org/10.1002/jez.1400640107

[17] Baumberger, J.P. and Glaser, R.W. (1917) The Rearing of Drosophila ampelophila Loew on Solid Media. Science, 45, 21-22.

https://doi.org/10.1126/science.45.1149.21-b

[18] Baumberger, J.P. (1917a) The Food of Drosophila melanogaster Meigen. Proceedings of the National Academy of Sciences of the United States of America, 3, 122-126. https://doi.org/10.1073/pnas.3.2.122

[19] Baumberger, J.P. (1917b) Solid Media for Rearing Drosophila. American Naturalist, 51, 447-448. https://doi.org/10.1086/279622

[20] Baumberger, J.P. (1919) A Nutritional Study of Insects, with Special Reference to Microorganisms and Their Substrata. Journal of Experimental Zoology, 28, 1-81. https://doi.org/10.1002/jez.1400280102

[21] Starmer, W.T. and Fogleman, J.C. (1986) Coadaptation of Drosophila and Yeasts in Their Natural Habitat. Journal of Chemical Ecology, 12, 1037-1055.

https://doi.org/10.1007/BF01638995

[22] Starmer, W.T., Barker, J.S.F., Phaff, H.J. and Fogleman, J.C. (1986) Adaptations of Drosophila and Yeasts: Their Interactions with the Volatile 2-Propanol in the Cactus-Microorganism-Drosophila Model System. Australian Journal of Biological Sciences, 39, 69-77.

[23] Anagnostou, C., Dorsch, M. and Rolfs, M. (2011) Influence of Dietary Yeasts on Drosophila melanogaster Life-History Traits. Entomologia Experimentalis et Applicata, 136, 1-11, https://doi.org/10.1111/j.1570-7458.2010.00997.x

[24] Deshpande, S.A., Yamada, R., Mak, C.M., Hunter, B., Obando, A.S., Hoxha, S. and Ja, W.W. (2015) Acidic Food pH Increases Palatability and Consumption and Extends Drosophila Lifespan. The Journal of Nutrition, 145, 2789-2796.

https://doi.org/10.3945/jn.115.222380 
[25] Ja, W., Carvalho, G.B., Zid, B.M., Mak, E.M., Brummel, T. and Benzer, S. (2009) Water and Nutrient-Dependent Effects of Dietary Restriction on Drosophila Lifespan. Proceedings of the National Academy of Sciences USA, 106, 18633-18637. https://doi.org/10.1073/pnas.0908016106

[26] Bridges, C.B. and Darby, H.H. (1933) Culture Media for Drosophila and the pH of Media. The American Naturalist, 67, 437-472. https://doi.org/10.1086/280505

[27] Bridges, C.B. (1933) Apparatus and Methods for Drosophila Culture. The American Naturalist, 66, 250-273. https://doi.org/10.1086/280430

[28] Morgan, T.H., Sturtevant, A.H., Muller, H.J. and Bridges, C.B. (1913) The Mechanism of Mendelian Heredity. Henry Holt and Company, New York.

[29] Anonymous (2015).

http://yeastgrrl.blogspot.com/2015/02/the-fly-room-new-film-about-thomas-hunt.h $\underline{\mathrm{tml}}$

[30] Smith, R.C. (1931) A Study of Temperature and Humidity Conditions in Common Types of Insect Rearing Cages. Journal of Agricultural Research, 43, 0547-0557.

[31] Butler, G.D. (1966) Development of Several Predaceous Hemiptera in Relation to Temperature. Journal of Economic Entomology, 59, 1306-1310. https://doi.org/10.1093/jee/59.5.1306

[32] Stinner, R.E., Gutierrez, A.P. and Butler, G.D. (1974) Algorithm for Temperature-Dependent Growth-Rate Simulation. Canadian Entomologist, 106, 519-524. https://doi.org/10.4039/Ent106519-5

[33] Butler, G.D., Henneberry, T.J. and Clayton, T. (1983) Bemisia-tabaci (Homoptera, Aleyrodidae)-Development, Oviposition, and Longevity in Relation to Temperature. Annals of the Entomological Society of America, 76, 310-313. https://doi.org/10.1093/aesa/76.2.310

[34] Visscher, S.N., Lund, R. and Whitmore, W. (1979) Host Plant-Growth Temperatures and Insect Rearing Temperatures Influence Reproduction and Longevity in the Grasshopper, Aulocara Elliotti (Orthoptera, Acrididae). Environmental Entomology, 8, 253-258. https://doi.org/10.1093/ee/8.2.253

[35] Manel, S. and Debouzie, D. (1997) Modeling Insect Development Time of Two or More Larval Stages in the Field under Variable Temperatures. Environmental Entomology, 26, 163-169. https://doi.org/10.1093/ee/26.2.163

[36] Sprugeon, D.W. and Brent, C.S. (2016) Development, Survival, and Hatching Periodicity of Lygus hesperus (Hemiptera: Miridae) Eggs under Constant and Variable Temperatures. Journal of Entomological Science, 51, 292-304.

https://doi.org/10.18474/JES16-17.1

[37] Hayes, D.K., Morgan, N.O. and Webb, R.E. (1991) Space Travel Shortens Diapause in Gypsy-Moth Eggs. Chronobiology International, 8, 75-83.

https://doi.org/10.3109/07420529109063921

[38] Roubaud, E. (1930) Evolutionary Suspension and Obligatory Larval Hibernation Provoked by the Heat, in the Common Mosquito, Culex pipiens L. the True Diapause and the Pseudo-Diapause in Insects. Comptes rendus hebdomadaires des seances de 1 academie des sciences, 190, 324-326.

[39] Lees, A.D. (1953) The Significance of the Light and Dark Phases in the Photoperiodic Control of Diapause in Metatetranychus ulmi Koch. Annals of Applied Biology, 40, 487-497. https://doi.org/10.1111/j.1744-7348.1953.tb02388.x

[40] Williams, C.M. (1953) Control of Pupal Diapause by Direct Action of Light on Insect Brain. Science, 140, 386. https://doi.org/10.1126/science.140.3565.386 
[41] Harris, F.A., Lloyd, E.P. and Lane, H.C. (1969) Influence of Light on Diapause in Boll Weevil .2. Dependence of Diapause Response on Narrow Bands of Visible Radiation and a Broad Band of Infrared Radiation Used to Extend Photoperiod. Journal of Economic Entomology, 62, 854. https://doi.org/10.1093/jee/62.4.854

[42] Roberts, R.H. (1927) Relation of Composition to Growth and Fruitfulness of Young Apple Trees as Affected by Girdling, Shading, and Photoperiod. Plant Physiology, 2, 273-286. https://doi.org/10.1104/pp.2.3.273

[43] Ito, K., Sugiyama, H. and Salleh, N. (1993) Effects of Lunar Phase on Light Trap Catches of the Malayan Black Rice Bug, Scotinophara coarctata (Heteroptera, Pentatomidae). Bulletin of Entomological Research, 83, 59-66. https://doi.org/10.1017/S000748530004178X

[44] Gu, H. and Danthanarayana, W. (1992) Influence of Larval Rearing Conditions on the Body Size and Flight Capacity of Epiphyas postvittana Moths. Australian Journal of Zoology, 40, 573-581. https://doi.org/10.1071/ZO9920573

[45] Claret, J. and Volkoff, N. (1992) Vitamin-A Is Essential for 2 Processes Involved in the Photoperiodic Reaction in Pieris brassicae. Journal of Insect Physiology, 38, 569-574. https://doi.org/10.1016/0022-1910(92)90108-P

[46] Lysyk, T.J. (1992) Effect of Larval Rearing Temperature and Maternal Photoperiod on Diapause in the Horn fly (Diptera, Muscidae). Environmental Entomology, 21, 1134-1138. https://doi.org/10.1093/ee/21.5.1134

[47] Ruberson, J.R., Bush, L. and Kring, T.J. (1991) Photoperiodic Effect on Diapause Induction and Development in the Predator Orius insidiosus (Heteroptera, Anthocoridae). Environmental Entomology, 20, 786-789. https://doi.org/10.1093/ee/20.3.786

[48] McCloud, E.S. and Berenbaum, M.R. (1994) Stratospheric Ozone Depletion and Plant-Insect Interactions-Effects of UVB Radiation on Foliage Quality of Citrus jambhiri for Trichoplusia ni. Journal of Chemical Ecology, 20, 525-539. https://doi.org/10.1007/BF02059595

[49] Connor, E.F. (2006) Effects of the Light Environment on Oviposition Preference and Survival of a Leaf-Mining Moth, Cameraria hamadryadella (Lepidoptera: Gracillariidae), on Quercus alba L. Ecological Entomology, 31, 179-184. https://doi.org/10.1111/j.0307-6946.2006.00779.x

[50] Collins, S.R., Weldon, C.W. and Taylor, P.W. (2008) Effects of Field Cage Colour and Supplementary Shade on Environmental Conditions and Mating Behaviour of Queensland Fruit Flies, Bactrocera tryoni. Entomologia experimentalis et applicata, 129, 142-147. https://doi.org/10.1111/j.1570-7458.2008.00765.x

[51] Tao, H., Li, X. and Qiu, J.-F. (2017) The Light Cycle Controls the Hatching Rhythm in Bombyx mori via Negative Feedback Loop of the Circadian Oscillator. Archives of Insect Biochemistry and Physiology, 96, Article Number: 321408. https://doi.org/10.1002/arch.21408

[52] Huaijian, L., Shi, L. and Liu, W. (2017) Effects of Light Intensity on the Flight Behaviour of Adult Tirumala limniace (Cramer) (Lepidoptera: Nymphalidae: Danainae). Journal of Insect Behavior, 30, 139-154. https://doi.org/10.1007/s10905-017-9602-8

[53] Patana, R. (1969) Rearing Cotton Insects in the Laboratory. U.S. Department of Agriculture Product Research Report 108, Washington DC.

[54] Patana, R. (1977) Rearing Selected Western Cotton Insects in the Laboratory. Volume 51 of ARS-W, United States Department of Agriculture, Berkeley, CA, 8 p.

[55] Economopoulos, A.P., Bruzzone, N.D. and Judt, S. (1987) Effect of Continuous 
Light and Oviposition Hole Size on the Egg-Production of Mediterranean Fruit-Flies Mass-Reared for Sterile Insect Technique Programs. In: Tonner, M., Soldan, T. and Bennetova, B., Eds., 4th International Symposium on Regulation of Insect Reproduction, Zinkovy, Czechoslovakia, Regulation of Insect Production: IV, 193-195.

[56] Cohen, A.C. (1985) Metabolic Rates of Two Hemipteran Members of a Predator-Prey Complex. Comparative Biochemistry and Physiology, 81A, 833-836. https://doi.org/10.1016/0300-9629(85)90915-6

[57] Klok, C.J., Kaiser, A.J. and Socha, J.J. (2016) Multigenerational Effects of Rearing Atmospheric Oxygen Level on the Tracheal Dimensions and Diffusing Capacities of Pupal and Adult Drosophila melanogaster. In: Roach, R.C., Wagner, P.D. and Hackett, P.H., Eds., Hypoxia: Translation in Progress, Book Series: Advances in EXperimental Medicine and Biology, Volume: 903, 285-300. https://doi.org/10.1007/978-1-4899-7678-9_20

[58] Terblanche, J.S., Klok, C.J. and Chown, S.L. (2004) Metabolic Rate Variation in Glossina pallidipes (Diptera: Glossinidae): Gender, Ageing and Repeatability. Journal of Insect Physiology, 50, 419-428. https://doi.org/10.1016/j.jinsphys.2004.02.009

[59] Harak, M., Kuusik, A. and Hiiesaar, K. (1998) Calorimetric Investigations on Physiological Stress in Tenebrio molitor (Coleoptera, Tenebrionidae) Pupae. Thermochimica Acta, 309, 57-61. https://doi.org/10.1016/S0040-6031(97)00422-X

[60] Schilman, P.E., Walters, J.S. and Harrison, J.F. (2011) Effects of Temperature on Responses to Anoxia and Oxygen Reperfusion in Drosophila melanogaster. Journal of Experimental Biology, 214, 1271-1275. https://doi.org/10.1242/jeb.052357

[61] Frazier, M.R., Woods, H.A. and Harrison, J.F. (2001) Interactive Effects of Rearing Temperature and Oxygen on the Development of Drosophila melanogaster. Physiological and Biochemical Zoology, 74, 641-650. https://doi.org/10.1086/322172

[62] Subramanyam, Bh. and Hagstrum, D.W. (1991) Quantitative Analysis of Temperature, Relative Humidity, and Diet Influencing Development of the Larger Grain Borer, Prostephanus truncatus (Horn) (Coleoptera: Bostrichidae). Tropical Pest Management, 37, 195-202. https://doi.org/10.1080/09670879109371581

[63] Cothran, V.R. and Gyrisco, G. (1966) A Container for Rearing Phytophagous Insects with Potential Application to Controlled Humidity Experiments. Journal of Economic Entomology, 59, 481. https://doi.org/10.1093/jee/59.2.481a

[64] Phillips, A.M. and Swingle, M.C. (1940) Rearing of Mosquito Larvae and Effect of Diet on Their Resistance to Rotenone and Nicotine. Journal of Economic Entomology, 33, 172-176. https://doi.org/10.1093/jee/33.1.172

[65] Inoda, T., Hasegawa, M., Kamimura, S. and Hori, S. (2009) Dietary Program for Rearing the Larvae of a Diving Beetle, Dytiscus sharpi (Wehncke), in the Laboratory (Coleoptera: Dytiscidae). The Coleopterist Bulletin, 63, 340-350. https://doi.org/10.1649/1152.1

[66] Keiper, J.B. and Foote, A. (1996) A Simple Rearing Chamber for Lotic Insect Larvae. Hydrobiologia, 339, 137-139. https://doi.org/10.1007/BF00008921

[67] Williams, D.D. and Williams, S.S. (2017) Aquatic Insects and Their Potential to Contribute to the Diet of the Globally Expanding Human Population. Insects, 8, 72. https://doi.org/10.3390/insects8030072

[68] Benedict, M.Q., Knols, B.G.J., Bossin, H.C., Herve, C., Howell, P.I., Mialhe, E., Caceres, C. and Robinson, A.S. (2009) Colonisation and Mass Rearing: Learning from Others. Malaria Journal, 8, S4, 11 p. 
[69] Merritt, R.W., Cummins, K.W. and Berg, M.B., Eds. (2008) An Introduction to the Aquatic Insects of North America. Kendall/Hunt Publishing Co., Dubuque, Iowa.

[70] Burgess, A.F. (1908) Description of New Devices for Rearing Insects. Journal of Economic Entomology, 1, 267-269. https://doi.org/10.1093/jee/1.4.267

[71] Shorey, H.H. (1963) A Simple Artificial Rearing Medium for the Cabbage Looper. Journal of Economic Entomology, 56, 536-537. https://doi.org/10.1093/jee/56.4.536a

[72] Shorey, H.H. and Hale, R.L. (1965) Mass-Rearing of the Larvae of Nine Noctuid Species on a Simple Artificial Medium. Journal of Economic Entomology, 58, 522-524. https://doi.org/10.1093/jee/58.3.522

[73] Tillman, P.G., McKibben, G., Malone, S. and Harsh, D. (1997) Form-Fill-Seal Machine for Mass-Rearing Noctuid Species. Remy, K.H., Ed., Office of Agricultural Communications, Division of Agriculture, Forestry, and Veterinary Medicine, Mississippi State University, Technical Bulletin 213, 1-4.

[74] Ignoffo, C.M. and Boening, O.P. (1970) Compartmented Disposable Plastic Trays for Rearing Insects. Journal of Economic Entomology, 63, 1696.

https://doi.org/10.1093/jee/63.5.1696

[75] Singh, P. and Surrey, M.R. (1980) A Plastic Container for Rearing Insects on Artificial Diets. New Zealand Journal of Zoology, 7, 441-442.

https://doi.org/10.1080/03014223.1980.10423799

[76] Cohen, A.C. and Staten, R.T. (1994) Long Term Culturing and Quality Assessment of Predatory Big-Eyed Bugs, Geocoris punctipes. In: Narang, S.K., Bartlett, A.C. and Faust, R.M., Eds., Applications of Genetics to Arthropods of Biological Control Significance, CRC Press, Boca Raton, FL, 122-132.

[77] Yamamoto, R.T. (1968) Mass Rearing of Tobacco Hornworm: 1 Egg Production. Journal of Economic Entomology, 61, 170-174. https://doi.org/10.1093/jee/61.1.170

[78] Bell, R.A. and Joachim, F.G. (1976) Techniques for Rearing Laboratory Colonies of Tobacco Hornworms and Pink Bollworms (Lepidoptera-Sphingidae-Gelechiidae). Annals of the Entomological Society of America, 69, 365-373. https://doi.org/10.1093/aesa/69.2.365

[79] Patana, R. (1977) Rearing Selected Western Cotton Insects in the Laboratory. Volume 51 of ARS-W, United States Agricultural Research Service. United States. Agricultural Research Service. Western Region. Department of Agriculture, Agricultural Research Service, Western Region, 8 p.

https://doi.org/10.5962/bhl.title.84526

[80] Ridgway, R.L., Morrison, R.K. and Badgley, M. (1970) Mass Rearing a Green Lacewing. Journal of Economic Entomology, 63, 834.

https://doi.org/10.1093/jee/63.3.834

[81] Patana, R. (1982) Disposable Diet Packet for Feeding and Oviposition of Lygus hesperus (Hemiptera, Miridae). Journal of Economic Entomology, 75, 668-669. https://doi.org/10.1093/jee/75.4.668

[82] Dillon, R.J. and Dillon, V.M. (2004) The Gut Bacteria of Insects: Nonpathogenic Interactions. Annual Review of Entomology, 49, 71-92.

https://doi.org/10.1146/annurev.ento.49.061802.123416

[83] Inglis, G.D. and Sikorowski, P.P. (2009) Microbial Contamination and Insect Rearing. In: Schneider, J.C., Ed., Principles and Procedures for Rearing High Quality Insects, Mississippi State University, MS State, 352, 150-222.

[84] Inglis, G.D. and Sikorowski, P.P. (2009) Entomopathogens and Insect Rearing. In: 
Schneider, J.C., Ed., Principles and Procedures for Rearing High Quality Insects, Mississippi State University, MS State, 223-288.

[85] Douglas, A.E. (1998) Nutritional Interactions in Insect-Microbial Symbioses: Aphids and Their Symbiotic Bacteria Buchnera. Annual Review of Entomology, 43, 17-37. https://doi.org/10.1146/annurev.ento.43.1.17

[86] Douglas, A.E. and Prosser, W.A. (1992) Synthesis of the Essential Amino-Acid Tryptophan in the Pea Aphid (Acyrthosiphon pisum) Symbiosis. Journal of Insect Physiology, 38, 565-568. https://doi.org/10.1016/0022-1910(92)90107-O

[87] Sandstrom, J.P., Russell, J.A., White, J.P. and Moran, N.A. (2001) Independent Origins and Horizontal Transfer of Bacterial Symbionts of Aphids. Molecular Ecology, 10, 217-228. https://doi.org/10.1046/j.1365-294X.2001.01189.x

[88] Nishide, Y., Naoko, T., Onodera, T., Tanahashi, M., Moriyama, M., Fukatsu, T., and Koga, R. (2017) Aseptic Rearing Procedure for the Stinkbug Plautia stali (Hemiptera: Pentatomidae) by Sterilizing Food-Derived Bacterial Contaminants. Applied Entomology and Zoology, 52, 407-415. https://doi.org/10.1007/s13355-017-0495-y

[89] Klepzig, K.D. and Six, D.L. (2004) Bark Beetle-Fungal Symbiosis: Context Dependency in Complex Associations. Symbiosis, 37, 189-205

[90] Six, D.L. (2012) Ecological and Evolutionary Determinants of Bark Beetle Fungus Symbioses. Insects, 3, 339-366. https://doi.org/10.3390/insects3010339

[91] Biedermann, P.H.W. and Rohlfs, M. (2017) Evolutionary Feedbacks between Insect Sociality and Microbial Management. Current Opinion in Insect Science, 22, 92-100. https://doi.org/10.1016/j.cois.2017.06.003

[92] Sikorowski, P.P. and Lawrence, A.M. (1994) Microbial Contamination and Insect Rearing. American Entomologist, 40, 240-253. https://doi.org/10.1093/ae/40.4.240

[93] Inglis, G.D. and Cohen, A.C. (2004) Influence of Antimicrobial Agents on the Spoilage of a Meat-Based Entomophage Diet. Journal of Economic Entomology, 97, 235-250. https://doi.org/10.1093/jee/97.2.235

[94] Funke, B.R. (1983) Mold Control for Insect-Rearing Media. Bulletin of the Entomological Society of America, 29, 41-44. https://doi.org/10.1093/besa/29.2.41

[95] Ludemann, L.R., Funke, B.R. and Goodpasture, C.E. (1979) Mold Control in Insect Rearing Media-Survey of Agricultural Fungicides and Evaluation of the Use of Humectants. Journal of Economic Entomology, 72, 579-582. https://doi.org/10.1093/jee/72.4.579

[96] Singh, P. and House, H.L. (1970) Antimicrobials: Safe Levels in a Synthetic Diet of an Insect. Agria affinis. Journal of Insect Physiology, 16, 1769-1782. https://doi.org/10.1016/0022-1910(70)90275-1

[97] Zha, C. and Cohen, A.C. (2014) Effects of Anti-Fungal Compounds on Feeding Behavior and Nutritional Ecology of Tobacco Budworm and Painted Lady Butterfly Larvae. Entomology, Ornithology and Herpetology, 3, 120.

[98] Vail, P.V., Henneberry, T.J., Kishaba, A.N. and Arakawa, K.W. (1968) Sodium Hypochlorite and Formalin as Antiviral Agents against Nuclear-Polyhedrosis Virus in Larvae of the Cabbage Looper. Journal of Invertebrate Pathology, 10, 84-93. https://doi.org/10.1016/0022-2011(68)90268-1

[99] Alverson, J. and Cohen, A.C. (2002) Effect of Antifungal Agents on Biological Fitness of Lygus hesperus (Heteroptera: Miridae). Journal of Economic Entomology, 95, 256-260. https://doi.org/10.1603/0022-0493-95.2.256

[100] Sinkins, S.P., Braig, H.R. and O’Neill, S.L. (1995) Wolbachia Superinfections and the Expression of Cytoplasmic Incompatibility. Proceedings. Biological Sciences, 
261, 325-330. https://doi.org/10.1098/rspb.1995.0154

[101] Werren, J.H. (1996) Biology of Wolbachia. Annual Review of Entomology, 42, 587-609. https://doi.org/10.1146/annurev.ento.42.1.587

[102] Werren, J.H., Baldo, L. and Clark, M.E. (2008) Wolbachia: Master Manipulators of Invertebrate Biology. Nature Reviews Microbiology, 6, 741-751. https://doi.org/10.1038/nrmicro1969

[103] Rani, A., Sharma, A., Rajagopal, R., Adak, T. and Bhatnagar, R.K. (2009) Bacterial Diversity Analysis of Larvae and Adult Midgut Microflora Using Culture-Dependent and Culture-Independent Methods in Lab-Reared and Field-Collected Anopheles stephensi-An Asian Malarial Vector. BMC Microbiology, 9, Article Number: 96. https://doi.org/10.1186/1471-2180-9-96

[104] Goettel, M.S. and Inglis, G.D. (2006) Methods for Assessment of Contaminants of Invertebrate Biological Control Agents and Associated Risks. In: Bigler, F., Babendreier, D. and Kuhlmann, U., Eds., Environmental Impact of Invertebrates for Biological Control of Arthropods. Methods and Risk Assessment, CABI Publishing. Wallingford, CT, 145-165. https://doi.org/10.1079/9780851990583.0145

[105] Lindsey, A.R.I. and Stouthamer, R. (2017) Penetrance of Symbiont-Mediated Parthenogenesis Is Driven by Reproductive Rate in a Parasitoid Wasp. PeerJ, 5, e3505. https://doi.org/10.7717/peerj.3505

[106] Kyei-Poku, G.K., Floate, K.D., Benkel, B. and Goettel, M.S. (2003) Elimination of Wolbachia from Urolepis rufipes (Hymenoptera: Pteromalidae) with Heat and Antibiotic Treatments: Implications for Host Reproduction. Biocontrol Science and Technology, 13, 341-354. https://doi.org/10.1080/0958315031000110355

[107] Bartlett, A.C. (1984) Genetic Changes during Insect Domestication. In: King, E.G. and Leppla, N.C., Eds., Advances and Challenges in Insect Rearing, USDA, ARS, New Orleans, LA, 2-8.

[108] Bartlett, A.C. (1994) Maintaining Genetic Diversity in Laboratory Colonies of Parasites and Predators. In: Narang, S.K., Bartlett, A.C. and Faust, R.M., Eds., Applications of Genetics to Arthropods of Biological Control Significance, CRC Press, Boca Raton, FL, 134-145.

[109] Thomas, D.B. (1993) Fecundity and Oviposition in Laboratory Colonies of the Screwworm Fly (Diptera: Calliphoridae). Journal of Economic Entomology, 86, 1464-1472. https://doi.org/10.1093/jee/86.5.1464

[110] Bush, G.L. and Neck, R.W. (1976) Ecological Genetics of Screwworm Fly, Cochliomyia hominivorax (Diptera-Calliphoridae) and Its Bearing on Quality-Control of Mass-Reared Insects. Environmental Entomology, 5, 821-826.

https://doi.org/10.1093/ee/5.5.821

[111] Babilonia, E.S. and Maki, D.L. (n.d.) (Website Posted by FAO) Mass Production of Sterile New World Screwworm Flies in Southern Mexico. Food and Agriculture Organization.

http://www.fao.org/docrep/u4220t/u4220T0g.htm\#facilities\%20for\%20mass\%20pro duction

[112] Brown, H.E. (1984) Mass Production of Screwworm Flies, Cochliomyia hominivorax. In: King, E.G. and Leppla, N.C., Eds., Advances and Challenges in Insect Rearing, USDA, ARS, New Orleans, LA, 193-199.

[113] Chaudhury, M.F. and Alvarez, L.A. (1999) A New Starch-Grafted Gelling Agent for Screwworm (Diptera: Calliphoridae) Larval Diet. Journal of Economic Entomology, 92, 1138-1141. https://doi.org/10.1093/jee/92.5.1138 
[114] Chaudhury, M.F., Skoda, S.R. and Sagel, A. (2011) Solidifying Agent and Processing of Blood used for the Larval Diet Affect Screwworm (Diptera: Calliphoridae) Life-History Parameters. Journal of Economic Entomology, 104, 1103-1107. https://doi.org/10.1603/EC10375

[115] Hendrichs, J. and Robinson, A. (2009) Sterile Insect Technique. In: Resh, V.H. and Carde, R.T., Eds., Encyclopedia of Insects, 2nd Edition, Academic Press, Elsevier Science Publisher, London, Oxford, Boston, New York and San Diego, 953-957. https://doi.org/10.1016/B978-0-12-374144-8.00252-6

[116] Parker, A.G. (2005) Mass-Rearing for sterile Insect Release. In: Dyck, V.A., Hendrichs, J. and Robinson, A.S., Eds., Sterile Insect Technique: Principles and Practice in Area-Wide Integrated Pest Management, Springer, Dordrecht, The Netherlands, 209-232. https://doi.org/10.1007/1-4020-4051-2_8

[117] Knipling, E.F. (1955) Possibilities of Insect Control or Eradication through Use of Sexually Sterile Males. Journal of Economic Entomology, 48, 459-462. https://doi.org/10.1093/jee/48.4.459

[118] Melvin, R. and Bushland, R.C. (1936) A Method of Rearing Chochliomyia Americana C. \& P. on Artificial Media. U.S. Bureau of Entomology and Plant Quarantine, Report et-88, Washington DC.

[119] Melvin, R. and Bushland, R.C. (1940) The Nutritional Requirements of Screwworm Larvae. Journal of Economic Entomology, 33, 850-852.

https://doi.org/10.1093/jee/33.6.850

[120] Gingrich, R.E., Graham, A.J. and Hightower, B.G. (1971) Media Containing Liquefied Nutrients for Mass-Rearing Larvae of the Screwworm. Journal of Economic Entomology, 64, 673-683. https://doi.org/10.1093/jee/64.3.678

[121] Bush, G.L., Neck, R.W. and Kitto, G.B. (1976) Screwworm Eradication: Inadvertent Selection for Noncompetitive Ecotypes during Mass Rearing. Science, 193, 491-493. https://doi.org/10.1126/science.941019

[122] Beckman, H.F., Bruckart, S.M. and Reiser, R. (1953) Laboratory Culture of the Pink Bollworm on Chemically Defined Media. Journal of Economic Entomology, 46, 627-630. https://doi.org/10.1093/jee/46.4.627

[123] Vanderzant, E.S. (1957) Growth and Reproduction of the Pink Bollworm on an Amino Acid Medium. Journal of Economic Entomology, 50, 219-221.

https://doi.org/10.1093/jee/50.2.219

[124] Vanderzant, E.S. (1958) The Amino Acid Requirements of the Pink Bollworm. Journal of Economic Entomology, 51, 309-311. https://doi.org/10.1093/jee/51.3.309

[125] Vanderzant, E.S. and Reiser, R. (1956) Aseptic Rearing of the Pink Bollworm on Synthetic Media. Journal of Economic Entomology, 49, 7-10.

https://doi.org/10.1093/jee/49.1.7

[126] Vanderzant, E.S. and Reiser, R. (1956) Studies of the Nutrition of the Pink Bollworm Using Purified Casein Media. Journal of Economic Entomology, 49, 454-458. https://doi.org/10.1093/jee/49.4.454

[127] Vanderzant, E.S., Reiser, R. and Ivy, E.E. (1956) Methods for the Mass-Rearing of the Pink Bollworm. Journal of Economic Entomology, 49, 559-560.

https://doi.org/10.1093/jee/49.4.559

[128] Vanderzant, E.S., Richardson, C.D. and Davich, T.B. (1959) Feeding and Oviposition by the Boll Weevil on Artificial Diets. Journal of Economic Entomology, 52, 1138-1142. https://doi.org/10.1093/jee/52.6.1138

[129] Adkisson, P.L., Vanderzant, E.S., Bull, D.L. and Allison, W.E. (1960) A Wheat Germ 
Medium for Rearing the Pink Bollworm. Journal of Economic Entomology, 53, 759-762. https://doi.org/10.1093/jee/53.5.759

[130] Vanderzant, E.S. (1967) Wheat-Germ Diets for Insects: Rearing the Boll Weevil1 and the Salt-Marsh Caterpillar. Annals of the Entomological Society of America, 60, 1062-1066. https://doi.org/10.1093/aesa/60.5.1062

[131] Stewart, F.D. (1984) Mass Rearing the Pink Bollworm, Pectinophora gossypiella. In: King, E.G. and Leppla, N.C., Eds., Advances and Challenges in Insect Rearing. USDA, ARS, New Orleans, LA, 176-187.

[132] Ouye, M.T. (1962) Effects of Antimicrobial Agents on Micro-organisms and Pink Bollworm Development. Journal of Economic Entomology, 55, 854-857. https://doi.org/10.1093/jee/55.6.854

[133] Stewart, F.D., Bell, R.B., Martinez, A.J., Roberson, J.J. and Lowe, A.M. (1976) The Surface Sterilization of Pink Bollworm Eggs and Spread of Cytoplasmic Polyhedrosis Virus in Rearing Containers. U.S. Department of Agriculture, Animal and Plant Health Inspection Service, APHIS-.81-27.

[134] Adkisson, P.L., Bull, D.L. and Allison, W.E. (1960) A Comparison of Certain Artificial Diets for Laboratory Cultures of the Pink Bollworm. Journal of Economic Entomology, 53, 791-793. https://doi.org/10.1093/jee/53.5.791

[135] Shaver, T.N. and Raulston, J.R. (1971) A Soybean-Wheat Germ Diet for Rearing the Tobacco Budworm. Annals of the Entomological Society of America, 64, 1077-1079. https://doi.org/10.1093/aesa/64.5.1077

[136] Ito, T. and Horie, Y. (1962) Nutrition of the Silkworm, Bombyx mori. VII. An Aseptic Culture of Larvae on Semi-Synthetic Diets. Journal of Insect Physiology, 8 , 569-578. https://doi.org/10.1016/0022-1910(62)90067-7

[137] Redfern, R.E. (1963) Concentrate Media for Rearing Red-Banded Leaf Roller. Journal of Economic Entomology, 56, 240-241. https://doi.org/10.1093/jee/56.2.240

[138] Martin, D.F. (1966) Pink Bollworm. In: Smith, C.N., Ed., Insect Colonization and Mass Production, Academic Press, New York, 355-366. https://doi.org/10.1016/B978-0-12-395601-9.50027-4

[139] Edwards, R.H., Miller, E., Becker, R., Mossman, A.P. and Irving, D.W. (1996) Twin Screw Extrusion Processing of Diet for Mass Rearing the Pink Bollworm. Transactions of the American Society of Agricultural Engineering, 39, 1789-1797. https://doi.org/10.13031/2013.27655

[140] Miller, E., Stewart, F., Lowe, A. and Bomberg, J. (1996) New Method of Processing Diet for Mass Rearing Pink Bollworm, Pectinophora gossypiella Saunders (Lepidoptera: Gelichiidae). Journal of Agricultural Entomology, 13, 129.

[141] Richmond, C.A. and Martin, D.F. (1966) Technique for Mass Rearing the Pink Bollworm. Journal of Economic Entomology, 59, 762-763. https://doi.org/10.1093/jee/59.3.762

[142] Hutchinson, G.E. (1965) The Ecological Theater and the Evolutionary Play. Yale University Press, New Haven, CT.

[143] Mackauer, M. (1972) Genetic Aspects of Insect Production. Entomophaga, 17, 27-48. https://doi.org/10.1007/BF02371071 